\title{
O circo em Ubu, Folias Physicas, Pataphysicas e Musicaes, espetáculo do Teatro do Ornitorrinco
}

\author{
Berenice Raulino
}

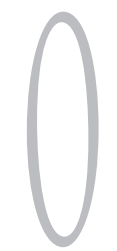

espetáculo Ubu, Folias Physicas, Pataphysicas e Musicaes estreou em 1985, no João Caetano, teatro do município da cidade de São Paulo: era uma mistura de circo, teatro popular, programa de auditório e show de música. A obra de Jarry incitava o diretor, Cacá Rosset, a dar rédea solta a sua imaginação, tendo como referência a Patafísica, ciência das soluções imaginárias ou ciência do particular que estuda as leis que regem as exceções, revelada pelo autor. ${ }^{1}$

Rosset pretendia que o interesse do público fosse despertado intensamente a cada momento e para tanto partiu da concepção dos futuristas russos da montagem de atraçōes. Como afirmou o diretor: "Na 'montagem de atraçôes' não interessa 'a descoberta das verdadeiras intenções do autor', 'a correta interpretação do autor', 'o verdadeiro reflexo da época', pois do ponto de vista formal fazer um bom espetáculo significa construir um bom programa de circo music hall, utilizando a situação básica da peça". ${ }^{2}$ Rosset tomou como base de seu roteiro o vislumbre de um espetáculo a ser elaborado a partir dos vetustos truques do teatro: "o alçapão, que é uma coisa super antiga, o urdimento, o ator pegando fogo. Quer dizer, são as coisas mais antigas do show business, e que são lindas. A gente quis usar esse lado do maravilhoso do teatro, quis trazer a teatralidade para o teatro". ${ }^{3}$

Berenice Raulino é professora de Teatro Brasileiro no Instituto de Artes da UNESP.

1 Cacá Rosset tomou como eixo da sua adaptação Ubu na Colina, peça em dois atos para marionetes e, a exemplo de Jarry, montou, desmontou, cortou e colou trechos das peças Ubu Rei ou Os Poloneses, Ubu Cornudo, Ubu na Colina, Almanaques do Pai Ubu, além de enxertar fragmentos de outros textos de Jarry no roteiro inicial. O texto efetivamente encenado foi sendo definido no decorrer dos ensaios e passou por diversas transformaçóes durante a temporada do espetáculo em cartaz. O personagem Ubu foi inspirado em um professor de física. Sua figura foi deformada por um dos seus alunos para quem aquele professor representava "todo o grotesco que houvesse no mundo", conforme declarou Jarry para a platéia, antes do início do espetáculo de estréia de Ubu Roi, em dezembro de 1896 (Levesque, 1954, p. 37). A intenção dos realizadores de trazer para a cena aquele universo fica patente na afirmação de Lina Bo Bardi no programa do espetáculo: "O que quisemos fazer, todos nós, quando montamos o $U b u$, era continuar aquela poética que é uma poética da infância e da primeira adolescência. Jarry é o iniciador da única vanguarda positiva que não morre: a vanguarda do cinismo e da destruição".

2 Cacá Rosset em entrevista ao IDART em 17 de julho de 1985.

3 Idem. 
A utilização de recursos circenses mesclados a trouvailles visuais teve como inspiração declarada diversos artistas. Eisenstein, Maiakóvski, Meyerhold, Jérôme Savary, Peter Brook e Giorgio Strehler foram alguns deles. Havia uma forte tendência no teatro europeu dos anos oitenta - a exemplo do que acontecera no início daquele século - de incorporar as artes circenses ao espetáculo teatral.

Cacá Rosset identificou a influência de Meyerhold principalmente nas cenas em que transparecia o rigor no enquadramento,${ }^{4}$ termo cinematográfico empregado por Eisenstein para designar a composição do quadro cênico dentro da encenação. Exemplos dessa influência são as cenas do exército polonês: a cena das pirâmides humanas em que as composições eram milimetricamente forjadas. Também, segundo Cacá: "Tem muita coisa à la Savary" no espetáculo. O circo é um recurso que ele usa muito e muito bem." [...] "Roubei essa idéia das bolinhas de uma montagem do Ubu do Peter Brook ${ }^{6}$ em que ele usava as bolinhas. Não exatamente desse jeito, não nessa quantidade, mas usava bolinhas de borracha". ${ }^{7} \mathrm{E}$ havia, sem dúvida, uma marca brechtiana na montagem. O princípio da antropofagia cultural e artística vigorava a pleno vapor.

A música, executada ao vivo pela Banda Patafísica, era um forte elemento narrativo e servia para realçar a tensão melodramática ou a comicidade de cada cena. Foram utilizadas a Traviata, a Marselhesa, obras de Miles Davis e os Barqueiros do Volga, entre outras. Muitas vezes a sonoplastia assemelhava-se à do desenho animado: as bolinhas, por exemplo, caíam com o som de tóim, quéim, quéim, o que reforçava o tom de brincadeira infantil. A música era contaminada pelo improviso presente na interpretação: mesmo os erros dos atores eram comentados por acordes musicais o que provocava um clima de riso permanente, além de grande expectativa na platéia de distinguir quais os efeitos já integrariam o espetáculo e quais as novidades daquela apresentação específica. A invenção que funcionasse passava a fazer parte do espetáculo que, no decorrer da temporada, sofreu várias alterações. $\mathrm{O}$ perigo desse tipo de procedimento é esgarçar a tessitura cênica e o Ornitorrinco não se furtou a esse risco.

A comunicação direta com a platéia própria do animador circense era realizada principalmente por José Rubens Chasseraux (Chachá) que conduzia muitas vezes o espetáculo como um mestre de cerimônias. A interpretação frontal dos atores estabelecia a comunicação direta $\mathrm{e}$ a cumplicidade com o público e ressaltava no espetáculo o tom jocoso. Ao dirigir-se à platéia Cacá Rosset estabelecia rupturas radicais. Em dado momento, a frase por ele proferida: "Eu não tô legal, sei lá... mil coisas" parecia vir de uma descompasso interior do ator e não do Pai Ubu. Em outra passagem, o mesmo Cacá - aí, evidentemente, investido de sua prerrogativa de diretor - declarava que ia encerrar naquele ponto o espetáculo. Esses procedimentos metalingüísticos eram também assumidos por Chachá; ao final de uma luta, por exemplo, um ator res-

4 O termo Mizankadr consta da tradução italiana das lições de Eisenstein, traduzido como Messa in inquadratura. Ver bibliografia.

5 Jérôme Savary (1942) diretor da Compagnie Jérôme Savary que se chamaria depois Le Grand Magic Circus et ses animaux tristes.

6 Ubu aux Bouffes, encenação de Peter Brook, no Théâtre Bouffes du Nord, Paris, em 1977. Jarry é para Brook o único autor francês próximo do espírito elizabetano. Naquela montagem, Brook utilizou também bobinas de madeira de diferentes dimensões como elementos cenográficos. Bobinas semelhantes seriam utilizadas por Ulysses Cruz no espetáculo Corpo de Baile, em 1988.

7 Entrevista ao IDART, em 17 de julho de 1985. 
tava deitado no palco e ele comentava com a platéia: "Não repara, viu? Aqui é assim: um ator por noite", sugerindo que o ator, de fato, morrera.

Um dos mais destacados jogos com a platéia era o desafio de que dois espectadores concorressem para dar um beijo na espiral desenhada na bochecha de Rosi Campos, a Mãe Ubu. Quando eles estavam já bem próximos, ela levantava sua saia e indicava uma outra espiral a ser beijada: desenhada sobre uma de suas nádegas. A brincadeira, evidentemente, constrangia os participantes, o que divertia ainda mais o público.

Em trabalhos anteriores do Ornitorrinco já estava presente a figura do ator performático; eram abertas brechas no espetáculo para que cada ator exibisse suas habilidades. Em Ubu, Folias Physicas, Pataphysicas e Musicaes esse procedimento foi incrementado, uma vez que a utilização de números circenses fazia parte da concepção original do espetáculo: atores e circenses se adestraram em técnicas corporais prevendo sua utilização em cena. Alguns integrantes do elenco tinham certo domínio anterior de artes circenses e se exercitaram para conseguir realizar os números idealizados pela direção. José Wilson Moura Leite, o diretor do Circo-Escola Picadeiro, orientou a preparação e responsabilizou-se pela instalação dos equipamentos necessários para a realização dos números no palco. José Rubens Chasseraux aprendeu a jogar malabares, a engolir e a cuspir fogo, embora não tenha utilizado essas técnicas na montagem. E assim como os atores se exercitaram na corda indiana, no trapézio, em saltos, no chicote, na pirofagia, também os circenses assumiram a função de atores, como Zé Wilson que, além de aprender a andar em monociclo especialmente para o espetáculo, acabou integrando o elenco da peça. E todos assumiam personagens ao desenvolver seus números, uma vez que o circo jamais aparecia desvinculado da ação.
Se muitas idéias para as intervenções circenses partiram de Rosset, existiu também o sentido inverso de direção: no decorrer dos ensaios foram surgindo propostas de soluções cênicas por meio de recursos do circo, sendo que a maioria delas acabou por fazer parte do espetáculo. Essa integração resultava em cenas em que as duas linguagens se associavam a ponto de constituir um só universo e outras nas quais a precisão técnica inerente ao circo fazia contraponto à improvisação que caracterizava o trabalho de atuação. A maquiagem era um fator importante nessa integração, pois tanto os atores como os circenses tinham seus rostos cobertos com a base branca dos palhaços, bochechas pintadas de vermelho vivo - em alguns casos compondo figuras geométricas triangulares -, grossas sobrancelhas, batom: exageros compatíveis com a estética circense que fortaleciam também a interpretação hiperbólica.

Os atores ficaram fascinados com o treinamento do circo, principalmente pela importância do rigor e da precisão, uma vez que qualquer descuido de um circense pode colocar em risco a sua própria integridade e também a de seu partner. Chachá, que além de ator foi assistente de direção, encarregando-se mais especificamente do trabalho dos atores, referiu-se da seguinte maneira àquela prontidão: "É uma ligação muito forte que os artistas de circo trazem para a cena, uma herança que eles trazem do circo. Não é esquecer uma fala: é cair do trapézio, ser engolido pelo leão, se queimar no fogo, é enterrar a faca no partner. Eles nunca ficam com o olhar perdido em cena. Não esquecem nada. Então, cinqüenta por cento do elenco ser circense já garante uma eficiência muito grande". ${ }^{8}$ A estética circense também contaminou a atuação. Reagir a comentários da platéia e incorporá-los à cena, como era feito, é próprio da tradição do palhaço e aproxima a representação do universo do público.

8 'Entrevista ao IDART em 13 de agosto de 1985. 
Nem sempre foi fácil atingir os resultados almejados. Cacá e Chiquinho haviam visto o espetáculo de Giorgio Strehler, Arlequim servidor de dois patróes, de Goldoni, no qual os elementos que compunham a cena de um jantar festivo eram trazidos ao palco por meio de malabarismos. Cacá quis transpor a composição para a cena do banquete de seu espetáculo e Zé Wilson recebeu a incumbência de montar complexos e cômicos números acrobáticos para o banquete. No entanto, como a cena não resultava bem, o diretor decidiu mudar sua concepção, optando pela contenção. $\mathrm{O}$ resultado ficou mais próximo da estética de Bob Wilson do que da commedia dell'arte de Strehler. Os artistas circenses, com malhas, chapéus de mestre-cuca e aventais brancos, atravessavam a cena lançando tortas, pernis e frangos cenográficos transformados em malabares e faziam cambalhotas. Luiz Ramalho dava um salto mortal com o frango na mão, número existente na montagem de Strehler para a execução do qual foi obrigado a um treinamento extra. Um pudim atravessava a cena, puxado por um cordão transparente, efeito também existente em Arlequim. Sobre a grande mesa do banquete era estendida uma longa toalha branca, mas os "alimentos" não permaneciam sobre ela. Os movimentos de Mãe e Pai Ubu, Capitão Bordadura e dos seus homens eram coreografados: todos esticavam os guardanapos diante de si, depois os colocavam sobre o peito, faziam um brinde etc., em gestual sincronizado. A orquestração do plano de matar o rei era representada de modo afinado. Embora apenas simulassem a existência da comida, Pai Ubu dava um sonoro arroto e, aproveitando o mote circense, um dos convivas reagia a uma comida supostamente apimentada cuspindo fogo: a sugestão partiu do intérprete e foi encampada pelo diretor: procedimento adotado freqüentemente.

Depois do assassinato do rei Venceslau, os soldados saltavam sobre o seu corpo, um sobre o outro, de maneira cruzada, formando uma pilha humana. Pai e Mãe Ubu jogavam um grande pano branco sobre essa pilha da qual os soldados saíam um a um. Pai Ubu fazia com gestos a marca do Zorro sobre o pano e Mãe Ubu atirava sangue sobre o suposto rei morto. Finalmente, Pai Ubu declarava: "Eu agora sou o rei deste país".

A linguagem circense foi paulatinamente integrando boa parte das cenas, como oportuna solução de problemas. $\mathrm{Na}$ cena em que apareciam os fantasmas dos ancestrais de Bugrelau, o legítimo herdeiro do trono, seria utilizada uma aparelhagem semelhante à de um páraquedas, mas, diante da dificuldade de execução daquele mecanismo, foi utilizada a corda indiana. Os circenses representando as figuras dos ancestrais executavam seus números com malhas inteiriças brancas que, sob o efeito da luz negra, transformavam-se em imagens espectrais, enquanto se ouvia uma voz em of: "Ouça, Bugrelau! Eu sou Matias de Konigsberg, primeiro rei, chefe e fundador da nossa casa real. Eu te confio, pequeno príncipe Bugrelau, a missão de nos vingar! E que tu, tu, pequeno príncipe Bugrelau, não encontre repouso enquanto viver o usurpador". Assim instado, Bugrelau sentenciava ameaçador: "Vinde a mim, miserável Pai Ubu!” O frágil príncipe ganhava dimensão ameaçadora por meio da fantasmagórica e singular projeção cênica de seus familiares.

Os festejos pela coroação de Pai Ubu eram constituídos por uma longa seqüência de números circenses. O novo rei anunciava: "Esta noite as portas do palácio se abrem para vocês! Portanto, é pão e circo!" E, enquanto ele e a Mãe Ubu iam sentar-se na platéia, iniciavam-se as comemorações. O cartaz trazido por um dos atores informava: "Este é o Palácio de Varsóvia" - em clara apropriação do recurso utilizado por Brecht. O Capitão Bordadura anunciava os números: dois trapézios por Los Hermanos Brothers, dança do ventre por Narjana: "rainha do oriente, mais fresca que uma coalhada, mais sensual que um quibe". Seguiam-se os Acrobatas Voadores e um grande show de pirofagia, que incluía saltos pelo centro de um aro em fogo e o manejo de malabares incandescentes. $\mathrm{O}$ palco ficava inteiramente iluminado pelo 
fogo e pelas fagulhas que voavam dos movimentos circulares dos malabares.

Um carteiro entrava em monociclo portando uma carta gigantesca para Mãe Ubu; tocava uma campainha imaginária, o que o obrigava a fazer uma pequena parada no monociclo. A sonoplastia realçava os movimentos e o som da campainha. A carta comunicava que o Capitão Bordadura, sentindo-se traído, pretendia unir-se ao czar para reconduzir $\mathrm{Bu}-$ grelau ao trono. A situação periclitante do casal Ubu ficava assim realçada pelo equilíbrio instável do monociclo.

Havia uma seqüência de números circenses para indicar o treinamento para a guerra realizado pelos soldados sob o comando do General Lascy. Os soldados entravam em fila indiana e, ao ouvirem: "Alto! Descansar!", sentavam-se um sobre o colo do outro. Quando o general solicitava um voluntário, o último da fila se oferecia, levantando-se, fazendo com que os demais caíssem no chão. Em seguir, recomposta a posição original, ao ouvir o comando "perna direita em frente, marche!" os soldados avançavam somente com a perna direita e novamente caíam todos. Quando o General Lascy dizia: "Passemos ao exercício 14 de sobrevivência na selva", um dos soldados começava a pular, imitando um macaco, dava cambalhotas e pulava no colo do general. Ao que ele retrucava: “14 e não 17, idiota!” Era então realizada a marcha da centopéia camuflada: cada soldado dava uma cambalhota, caía sentado no chão e encaixava-se com as pernas abertas às costas do da frente. Cada cambalhota era sinalizada por um apito do comandante. Depois, virando-se, todos ao mesmo tempo, para o chão, subiam um sobre as costas do outro e, caminhando, atravessavam como uma centopéia o palco e o general satisfeito gritava: "Viva as Forças Armerdras!". A ridicularização do exército era evidente.
Uma das criações dos circenses foi inserir um cavalo de pano, vestido por dois participantes, que conduzia Pai Ubu para a Guerra, tornando-o uma figura ainda mais jocosa, uma vez que não era fácil para Pai Ubu, com sua grande pança postiça, montar naquele cavalo de pano. O cavalo surgia em cena com uma domadora que utilizava um chicote para comandar seus movimentos, como os grandes animais são conduzidos no circo9 ${ }^{9}$. Por sua vez, os soldados compunham diferentes formações de pirâmides humanas com o intuito de observar o inimigo, o que faziam por meio de binóculos de plástico coloridos.

As czaretes abatiam, com golpes acrobáticos o exército polonês e o czar incendiava as costas de um soldado daquele exército. $\mathrm{O}$ circense para realizar este número vestia um casaco especial embebido em substância inflamável, saía correndo incendiado e assim que chegava na coxia, fora da vista do público, tinha o fogo em suas costas apagado por meio de um extintor de incêndio.

Além dos números especificamente circenses, havia diversos achados cênicos, alguns já sugeridos pelo próprio Jarry em suas obras, como o Polochon, o porco de duas bundas, executado em papel machê cor de rosa, que deslizava pela cena. $\mathrm{O}$ ciclismo sempre fascinou o escritor e dramaturgo francês que se situava "na ponta extrema do simbolismo" (Corvin, 1991, p. 451). No espetáculo, uma atriz caracterizada como o autor surgia, no início e no final da função, andando de bicicleta e, em outros momentos, um monociclo e uma longa bicicleta para cinco pessoas atravessavam a cena, retomando o "tempo de universal ciclismo" jarryiano.

Logo no início do espetáculo, uma apresentação era feita pelo ator Chiquinho Brandão - com a maquiagem já mencionada - tendo por figurino apenas sapatilhas pretas de dança,

9 Em conferência pronunciada antes da estréia da peça, Jarry fez menção a cavalos de papelão. 
meias soquete brancas e um chapéu coco preto como tapa sexo que era segurado a princípio por uma das mãos do ator, depois pela outra e, finalmente, por nenhuma. E lá permanecia!

Em dúvida sobre a oportunidade de assassinar o Rei Venceslau para usurpar o trono da Polônia, Pai Ubu consultava sua consciência. Rosset entrava pela direita, com uma grande mala na mão, e quando estava próximo ao meio do palco, apoiava-a no chão e, a abria: dela surgia -maquinada por um elevador do alçapão - a figura nua de sua consciência. Ao sair de cena, a mala era conduzida da mesma maneira que entrara, de modo a encobrir a ausência de seu fundo. Para tornar a cena ainda mais bizarra, na extremidade esquerda do palco estava Chiquinho Brandão tocando serrote, instrumento que aprendera especialmente para aquela cena.

Os nobres, os juízes - representados por dois participantes, um montado nas costas de outro, e cobertos por longas togas-, os financistas e até o papa polonês eram atirados em um alçapão; antes da queda, porém, recebiam um golpe de um grande porrete cenográfico de espuma desferido pelo Capitão Bordadura.
O czar era conduzido por duas czaretes dentro de uma caixa vermelha com rodinhas que lembrava uma caixa de surpresas. Ele próprio abria a parte superior e um lado da caixa e desenrolava, com um só golpe, um tapete vermelho antes de sair. No decorrer de suas falas, sentava-se sobre a tampa da caixa, enquanto as czaretes, vestidas apenas com a parte inferior de biquínis, botas e adereços brancos nas cabeças, cruzavam uma foice e um martelo sobre ele.

Ao final de suas façanhas, Pai e Mãe Ubu fugiam para a França em um balão.

Poderíamos considerar que, na montagem de Ubu, Folias Physicas, Pataphysicas e Musicaes, os recursos circenses extrapolavam o mero caráter ilustrativo; além de dar o tom geral do espetáculo, eles pontuavam de modo significativo o desenvolvimento da trama. Os estados de espírito dos personagens eram, várias vezes, explicitados pelas atrações circenses. A narrativa ali consubstanciada acentuava o caráter lúdico da ação e, ao mesmo tempo, sinalizava um certo sarcasmo. A livre associação entre os números circenses e circunstâncias objetivas potencializava a virtual reflexão sobre a realidade. 


\section{Referências bibliográficas}

BANU, G. et al. Brook. Paris: Editions du CNRS, 1985.

CORVIN, M. Dictionnaire encyclopedique du theatre. Paris: Bordas, 1991.

EJZENSTEJN, S. M. Lezioni di regia. Torino: Einaudi, 1999.

FERNANDES, S. Grupos teatrais - Anos 70. Campinas: Editora da UNICAMP, 2000.

JARRY, A. Ubu-Rei. Prefácio de Cacá Rosset. São Paulo: Max Limonad, 1986.

LEVESQUE, J. H. Alfred Jarry. Paris: Pierre Seghers, 1954.

\section{Entrevistas}

Cacá Rosset, concedida ao IDART/CCSP em 17 de julho de 1985.

Cacá Rosset, no site <www.festivaldeteatro.com.br/ftc_2004_site/entrevistas>. Acessado em: 19.01.2006.

José Rubens Chasserraux, concedida ao IDART/CCSP em 13 de agosto de 1985.

Lina Bo Bardi, concedida ao IDART/CCSP em 14 de junho de 1986. 